Bill Stonor

is a senior partner with

FaulknerBrowns, architects and leisure specialists, and a member of the International Union of Architects Sports and Leisure Working Group.

Keywords:

compact, development of brief, feedback, flexibility, landmark, value for money

Five aquatic disciplines

$1 \%$ versus $99 \%$

Mr Bill Stono

FaulknerBrowns

Dobson House

Northumbrian Way, Killingworth Newcastle-upon-Tyne NE12 oQW Tel: +44 (o) 1912683007

\section{The Design of Manchester Aquatics Centre}

\author{
Bill Stonor \\ Received: 2nd October, 2000
}

\begin{abstract}
FaulknerBrowns specialise in sports and commercial leisure developments, and have designed 150 projects containing swimming pools. The Manchester Aquatics Centre is their latest pool, completed in July 2000. This paper describes the development of this project.
\end{abstract}

\section{INITIAL BRIEF}

\section{Commonwealth Games}

Having won the bid for the 2002 Commonwealth Games, the city of Manchester required a new pool complex for the five aquatic disciplines:

- swimming

- diving

- water polo

- synchronised swimming

- synchronised diving

\section{The city and universities' community}

At the same time, and more importantly in terms of best value, Manchester city and the three central universities, Manchester Victoria, UMIST and Manchester Metropolitan, required a community recreational and clubs pool facility.

\section{DEVELOPMENT OF THE BRIEF}

FaulknerBrowns were selected to undertake a feasibility study to develop a more detailed brief, select a site and establish a budget.

The key consideration was how to balance the 1 per cent needs of the Commonwealth Games (two weeks in a 50-year lifetime) with those of a 99 per cent community facility. While this would be only the third new $50 \mathrm{~m}$ pool complex to be built since the Edinburgh Commonwealth Pool in the 1960s, and only the tenth $50 \mathrm{~m}$ pool to come into operation out of a UK portfolio of 1,600 public pools, revenue economics dictated that the pool could only be afforded if it had wide public usage. There therefore had to be a serious attempt to satisfy both needs well.

\section{Feedback from Ponds Forge international pool}

The last $50 \mathrm{~m}$ aquatics centre to be completed in the UK was in the Ponds Forge international sports complex at Sheffield in 1990. The 
Three key decisions

\section{Movable floors for flexibility}

Permanent and temporary seats pool element of this complex covered $15,000 \mathrm{~m}^{2}$ and included permanent seating for 3,000 spectators.

In respect of the Manchester project, three important decisions were made in consultation with the Amateur Swimming Federation of Great Britain (ASFGB), Sport England and the Manchester client.

- Ponds Forge, which is less than 40 miles from Manchester, would remain the UK's premier international spectator pool and would continue to host the majority of national and international events.

- This decision would mean that the Manchester project need not be so comprehensive in its provision for regular international events. It could therefore be targeted to be 75-80 per cent of the overall size of Ponds Forge, thereby saving substantially on both capital costs and, more importantly, on annual revenue expenditure. Of the 1,600 public swimming pools in the UK, fewer than ten manage to balance expenditure with income.

- The use of movable floors to allow $2 \mathrm{~m}$ deep water for competitive racing (the FINA requirement for world-class venues to avoid the turbulence to swimmers from vortex reflection off the pool bottom) and shallower waters for swimming lessons and recreational swimming had proved to be a great success.

\section{Spectators}

The greatest challenge in the design of the Manchester Aquatics Centre was the resolution of the problem of spectator numbers. The Commonwealth Games required 2,500 seats, yet the maximum number required for other events in the lifetime of the pool would normally be 1,250 seats.

This led to a decision to provide only 1,250 permanent seats in the Manchester complex, with the facility to provide an additional 1,250 temporary seats solely for the Commonwealth Games.

\section{Schedule of accommodation}

Following a detailed value assessment of each element, the final mix of facilities (see figure 1) was determined to be:

- a pool hall containing:

- a $50 \mathrm{~m} \times 21 \mathrm{~m} \times 2 \mathrm{~m}$ deep main pool with two recessible booms to create a $25 \mathrm{~m}$ swimming course and a smaller area for swimming lessons; two large movable floors within the pool create shallower waters for fun swimming, recreation and swim lessons

- a $25 \mathrm{~m} \times 16.5 \mathrm{~m} \times 5 \mathrm{~m}$ deep diving/multipurpose pool with a movable floor over the whole area

- $250 \mathrm{~m}^{2}$ of permanently shallow leisure and fun waters with two flume rides; because this area will not be used for the 


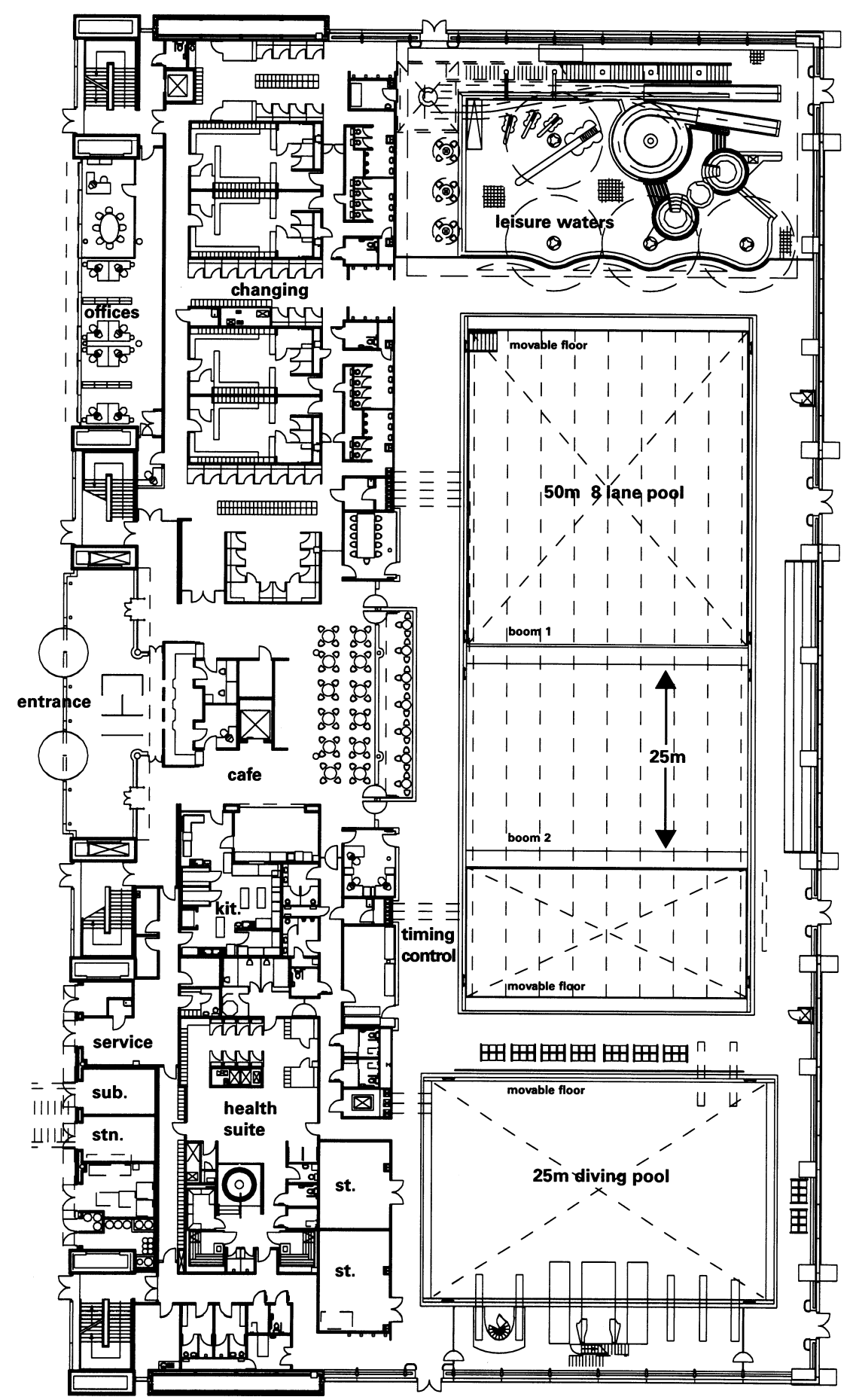

Figure 1

Commonwealth Games it provides the opportunity for the erection of 800 temporary spectator seats for the Games;

- a café area for 60-100 covers, located to be seen at the point of entry to the complex and to open out into the main pool hall;

- a health and fitness suite of $750 \mathrm{~m}^{2}$ comprising: 


\section{Fitness suite}

\section{National Standard high performance training pool}

\section{Prominent and central location}

\section{Compact plan}

- two fitness areas containing 75 machines

- a $160 \mathrm{~m}^{2}$ multipurpose studio

- a $200 \mathrm{~m}^{2}$ health area with spa pool, two saunas, steam room, sunbeds and lounge area, all of these spaces would be accessible to the main pool hall and its spectator gallery, so that they could be used as support spaces for the Commonwealth Games (press room, VIPs and officials, etc);

- a children's crèche and fun play area of $120 \mathrm{~m}^{2}$;

- ancillary accommodation:

- entrance foyer

- changing rooms

- administration offices

- heating, ventilation, electrical and water treatment plantrooms;

- late on in the design process, Sport England and the Amateur Swimming Association decided to add a national-standard highperformance $50 \mathrm{~m}$ training pool, primarily for the use of worldclass and world-class potential swimmers; this will be one of four national network pools for the English Institute of Sport.

\section{Total area and budget}

Accommodation then grossed up to $12,000 \mathrm{~m}^{2}$, and a pool building budget of $£ 22 \mathrm{~m}$ was set for the building, its specialist equipment and the infrastructure and external works.

\section{SITE SELECTION}

\section{Location}

The key consideration was to achieve a prominent and central location. This pointed towards a relatively small site at the conjunction of the three universities on the main Oxford Road. Due to the supportive attitudes and determination of the universities, Manchester city and Sport England, the site was enlarged by UMIST relocating an existing accommodation block and by Manchester Victoria University providing an adjacent site for a multi-storey car park.

The pool complex site then allowed a maximum footprint of $5,500 \mathrm{~m}^{2}$, and this determined a compact plan with a basement of $3,500 \mathrm{~m}^{2}$, a ground floor of $5,500 \mathrm{~m}^{2}$ and an upper level of $3,000 \mathrm{~m}^{2}$.

\section{DESIGN CRITERIA}

The following design criteria were agreed with the combined client group. These led to the final design solution.

- The pool should impact on to the busy Oxford Road in terms of a strong architectural identity and in providing views for the passing public into the main pool hall. 


\section{Diving boards were the determinants of the cross-section}

The children's leisure pool is placed at the Oxford Road end of the building so that more distant views of the diving and $50 \mathrm{~m}$ pool are glimpsed through the palm trees. A large portion of the gable wall is glazed with units containing electronically adjustable blinds so that glare can be controlled. The huge swoop of the roof form identifies the complex.

- The building mass and external materials should be sensitive to the location - especially to the new UMIST business school, its immediate neighbour on Oxford Road - and the horseshoe cluster of residential blocks at the opposite end.

The $19 \mathrm{~m}$-high arched roof pivots on a $10 \mathrm{~m}$-high ancillary block which is the same height as the business school and uses stone from the same quarry as a major cladding material. The far gable of the pool hall transforms the residential horseshoe into a delightful quadrangle.

- The pool hall interior should be dramatic yet friendly in scale and colour.

The main determinants of cross-sectional height and shape were the zones of clear space required above each of the diving stages. The location of the $10 \mathrm{~m}$-high diving platform on the centre line of the pool hall with the other diving stages set off to the sides enables the northern roof line to arch steeply downwards to a low external wall and the southern roof to gently touch the ancillary block (see figure 2). The resultant volume with its quilt-like acoustic soffit provides a comforting cocoon in contrast to the awesomeness of the Ponds Forge international pool hall at Sheffield.

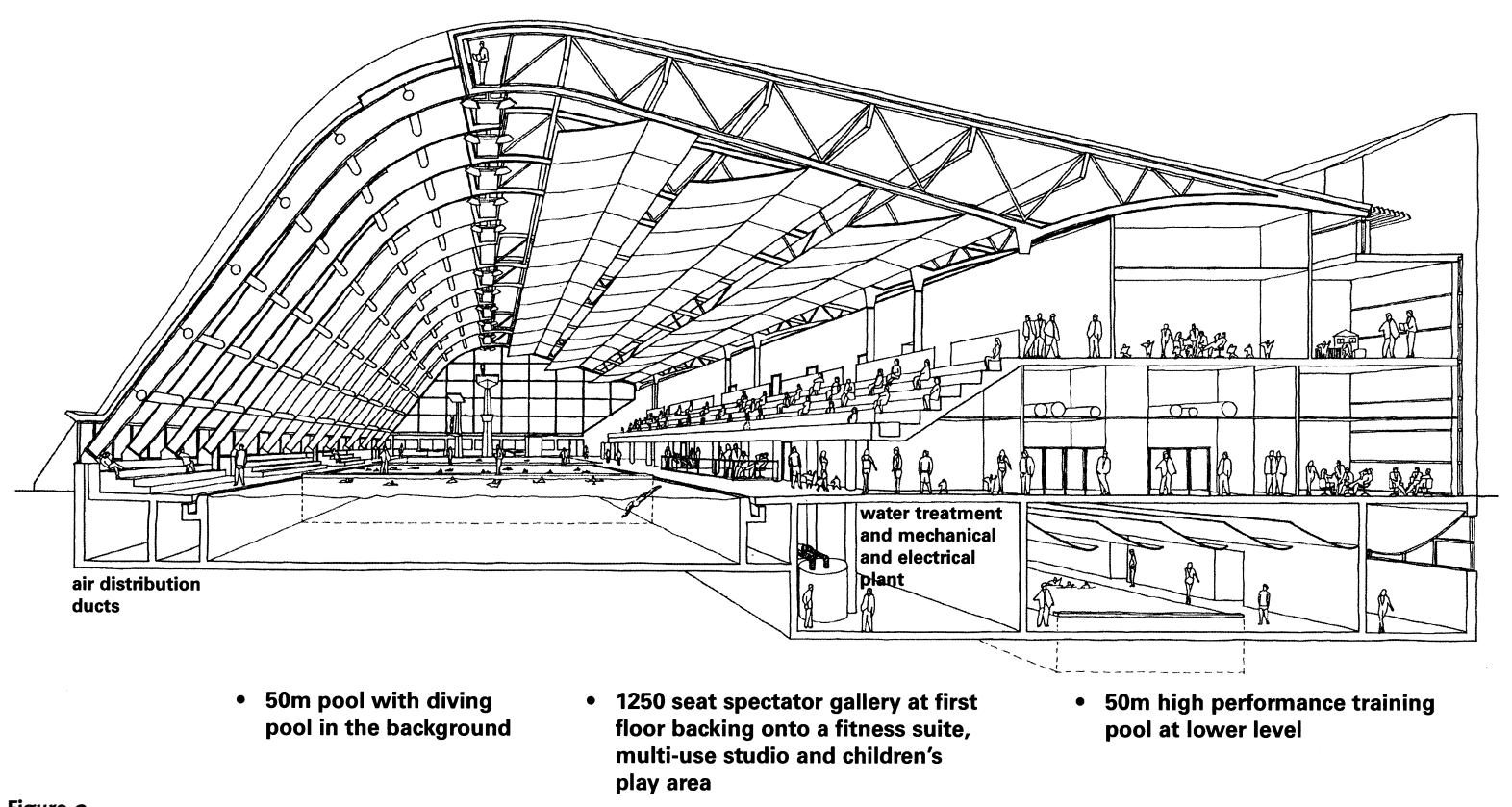

Figure 2

floor backing onto a fitness suite, play area 
- The layout should be easily comprehensible and management conscious.

The plan layout has a classical simplicity. The four staircases required for means of access and escape divide the complex into three equal zones. The middle zone contains the main entrance, which has views of the pool through the café area which also opens on to a patio within the pool hall itself. To the left of the entrance is the western zone containing changing accommodation, and to the right is the eastern zone with the health suite, kitchen and specialist pool stores and control rooms. One floor down is the English Institute of Sport high performance $50 \mathrm{~m}$ training pool, with a sinuous curved ceiling swooping below lift-shaft pits and service ducts and arcing up to provide maximum height for swimmers on raised starting blocks at each end of the pool. On either side of the entrance are the stairs, which lead to the upper level containing the spectator gallery, children's play area, the fitness suite and multi-use dance studio.

- The building should be energy efficient.

The overall building form is very compact, with 30 per cent of volume recessed into the ground as a basement. The varying height of the main pool is dictated by the space required above the various diving stages. The envelope area is therefore exceptionally low for a building of this nature, and high levels of insulation ensure the minimum need for artificial systems. The complex runs efficiently, using a comprehensive system of heat exchangers with some cleansing and recycling of the pool atmosphere.

- Water treatment should be appropriate.

The quality of the water in the various swimming pools is the most important physical ingredient in the complex. The shallow leisure waters will be heavily used and this pool has ozonation as well as an excellent traditional sand-bed filtration system. The $50 \mathrm{~m}$ training-for-excellence pool has onerous requirements too, as world-class swimmers will train for long hours here. This pool has partial ozonation to enable chlorine levels to be minimised and 'red eye' to be avoided. The main $50 \mathrm{~m}$ pool, because of its $2 \mathrm{~m}$ basic depth, will have more traditional requirements, but the overall water distribution system is valved so that it too can be flushed with ozonated water occasionally.

Movable floors, booms \& bubblers
- the largest area of movable floors in one complex in the world, $1,360 \mathrm{~m}^{2}$ 
The spirit of the Latham Report

\section{Secure fixed price}

A landmark building
- main $50 \mathrm{~m}$ pool $-23.7 \mathrm{~m} \times 21 \mathrm{~m}+10 \mathrm{~m} \times 21 \mathrm{~m}$

- diving pool $-16.5 \mathrm{~m} \times 25 \mathrm{~m}$

- $50 \mathrm{~m}$ training pool $-25 \mathrm{~m} \times 10 \mathrm{~m}$

- three booms which sub-divide the pool areas

- a $3 \mathrm{~m}$-wide $10 \mathrm{~m}$ diving platform to accommodate the new aquatics sport of synchronised diving

- a bubbler system on the floor of the diving pool which provides giant bubbles released during diving training sessions to cushion the divers' impact with the water and prevent injuries.

\section{CONTRACT PROCUREMENT}

The two-stage tender process followed the spirit of the Latham Report in bringing closer together the designer and the builder to the benefit of the product and the client. The key considerations were to employ a method which allowed the procurement of a high quality building with a high degree of cost certainty.

After the initial designs had been produced, Stage 1 tenders were sought only in respect of preliminary costs and the contractor's fee. Tenderers were also rigorously assessed in terms of their resources, key personnel and organisational skills, and this qualitative assessment formed an element of the marking process alongside their cost tenders.

The Stage 1 tenders amounted to around 10 per cent of the total capital cost and Laing were the successful contractor. The contractor, in partnership with the design team, sought tenders for around 50 work packages which constituted the total build of constructional, servicing and finishing elements. During this fivemonth period, the design team worked alongside the contractor in developing the detailed design of all elements, and the scheme undoubtedly benefited from this partnering liaison. When all subcontract tenders had been agreed, the contractor was then able to formulate a secure fixed price for which he took responsibility. Following negotiation with the client, this price was adjusted and the contract was formally entered into for around $£ 22 \mathrm{~m}$ for the contractor to undertake the works on site.

The contract was conducted with goodwill between all parties, with the designers novated to the contractor to complete final drawings and to assist the contractor in procuring the required quality. It has been a happy contract which was finished ten weeks ahead of programme and within the secure fixed price, negotiated before work started on site.

This procurement method is being promoted on other similar projects.

\section{SUMMARY}

A landmark building has been created for the city of Manchester, its three universities, the Amateur Swimming Association and Sport England. The aquatics centre sits comfortably within its urban context and, in particular, enhances the setting of the adjacent 
UMIST Federal School. The building is well built and the standard of internal finish is high.

The management team, SERCO, was appointed three months before completion of the contract and the aquatics centre was opened to the public in the middle of September 2000. The building will therefore have nearly two years of usage and testing before the Commonwealth Games in 2002. 